\title{
Rare Primary Pulmonary Primitive Neuroectodermal Tumor: A Case Report and Literature Review
}

This article was published in the following Dove Press journal: OncoTargets and Therapy

Ning Wang, ', ShuangShuang Dong, $\mathbb{D}^{1, *}$ ChunLin $\mathrm{Wu},{ }^{2}$ Ying Wang, ${ }^{3}$ Lian Meng,' Yan Ren,' XiaoBin Cui, ' Man Li, ' Yan $\mathrm{Qi}^{1,4}$

'Department of Pathology, Shihezi University School of Medicine, The First Affiliated Hospital to Shihezi University School of Medicine, Shihezi, Xinjiang 832002, People's Republic of China; ${ }^{2}$ Key Laboratory for Green Processing of Chemical Engineering of Xinjiang Bingtuan, Shihezi University, Shihezi, Xinjiang 832002, People's Republic of China; ${ }^{3}$ Department of Stomatology, Shihezi University School of Medicine, Shihezi, Xinjiang 832002, People's Republic of China; ${ }^{4}$ Department of Pathology, Certral People's Hospital of Zhanjiang \& Zhanjiang Central Hospital, Guangdong Medical University, Zhanjiang, People's Republic of China

*These authors contributed equally to this work
Correspondence: Man Li

Department of Pathology, Shihezi University

School of Medicine \& The First Affiliated

Hospital to Shihezi University School of

Medicine, North 2 Road, Shihezi, 832002

Xinjiang, People's Republic of China

Tel +86 I8799075I6I

Email243083166@qq.com

Yan Qi

Department of Pathology, Certral People's Hospital of Zhanjiang \& Zhanjiang Central Hospital, Guangdong Medical University,

Zhanjiang, People's Republic of China

Tel +86 +86 I5009932652

Email qiyanyan-1998@I63.com

\begin{abstract}
Primitive neuroectodermal tumors (PNETs) arising from the lung without thoracic wall involvement are extremely rare and particularly aggressive neoplasms. Herein, we present the case of a 41-year-old woman with pulmonary PNET diagnosed following histopathological, immunohistochemical, and molecular pathological examination of a surgical biopsy specimen. The case report is accompanied by a literature review of primary pulmonary PNETs.
\end{abstract}

Keywords: primitive neuroectodermal tumor, pulmonary, differential diagnosis

\section{Introduction}

Peripheral primitive neuroectodermal tumors (PNETs) are rare malignancies that occur most commonly in extraskeletal and soft tissues during childhood or adolescence. Pathologically, PNETs are part of the small round cell sarcoma family, which are characterized by neuroectodermal differentiation. Kushner et al first described 54 cases of PNET in 1991. ${ }^{1}$ Such tumors primary in the thoracopulmonary region are commonly known as Askin tumors. ${ }^{2,3}$ PNET and Askin tumors are collectively referred to as extraskeletal Ewing sarcomas. As members of the Ewing family, PNET, Askin tumors, and Ewing sarcoma are characterized by EWRS1 fusion on chromosome 22 and ETS family transcription factors. Most cases $(85 \%)$ have $\mathrm{t}(11 ; 22)$ (q24; q12) translocation and form EWSR1-FLI1 fusion genes. A previous study demonstrated that the disease may originate from the chest wall $(33.3 \%)$ and pelvis $(22.2 \%)$ most commonly, other common sites include paraspinal region (13.0\%), retroperitoneum $(11.1 \%)$, limbs (9.3\%), abdomen $(7.4 \%)$, neck $(1.9 \%)$, and unknown sites $(1.9 \%),{ }^{1}$ but it rarely arises from the lung. PNETs that arise in the lung parenchyma without chest wall involvement are extremely rare in adults; to the best of our knowledge, only 28 cases have been described in the English literature. Herein, we report a rare case of primary pulmonary PNET and its pathological characteristics.

\section{Case Report}

A 41-year-old woman presented with persistent dry cough and low-grade fever $\left(37.5^{\circ} \mathrm{C}\right)$ for one week. Pulmonary computed tomography $(\mathrm{CT})$ revealed a localized lesion in the left upper lung lobe. The lesion was close to the pulmonary capsule, 
with a maximum diameter of $1.9 \mathrm{~cm}$. We considered the possibility of benign lesions at first.

During further examination, a pathologist performed a fine-needle cytology smear. After hematoxylin-eosin staining, red blood cells were observed throughout the field under the microscope. Moreover, a few scattered heterotypic cells were observed in these red blood cells. The heterotypic cells had naked nuclei and the nucleus chromatin was fine and smooth, resembling those typical of small cell lung cancer (SCLC). However, the wiredrawing phenomenon was not obvious (Figure 1A). Therefore, we provided a descriptive examination without a specific diagnosis at the time.

The patient underwent a mass and partial lung resection with biopsy. A surgeon excised irregularly shaped tissue, which included tumor and surrounding lung tissue, with the following dimensions: $5.6 \mathrm{~cm} \times 5.1 \mathrm{~cm} \times 2.1 \mathrm{~cm}$. Upon sectioning of the tissue, a solid cystic nodule $(1.9 \mathrm{~cm} \times$ $1.5 \mathrm{~cm} \times 0.9 \mathrm{~cm}$ ) was found close to the pulmonary capsule (Figure 1B). The solid area was grayish red and yellow with fine texture, while the cystic area had hemorrhage and necrosis.

Histopathological examination of the specimen revealed dense neoplastic tissue in the lung tissue margins. The neoplastic cells were composed of small blue round cells (Figure 1C); most tumor cells were in a lamellar arrangement, while some were in a hemangiopericytomalike arrangement (Figure 1D). The small round blue cells exhibited neuroectodermic differentiation. Homer-Wright chrysanthemum-shaped clusters were present, and their axes were neurofibrillary substances. At high magnification, the tumor cells had round or oval nuclei, clear nuclear membranes, and fine and uniform nuclear chromatin, resembling dust or pepper (Figure 1E, F).

Immunohistochemical staining showed that the tumor cells expressed vimentin (Figure 2A), Fli-1 (Figure 2B), and CD99 (Figure 2C) proteins, while the expression of CgA, Syn, CK5/6, and protein S-100 were negative. Onestep reverse transcription polymerase chain reaction showed that the tumor cells had specific heterotopic fusion genes, EWSR1-FLI1 (Figure 2D). Combining the morphologic, immunohistochemical, and molecular findings, we were able to diagnose the patient with primary pulmonary PNET.

Following diagnosis, the patient did not undergo treatment (eg, radiotherapy or chemotherapy) other than surgical resection. Follow-up visits were scheduled every three months; after 18 months, the patient showed no signs of recurrence.

\section{Discussion}

PNET is a highly aggressive soft tissue sarcoma. The tumor is part of the Ewing sarcoma family and occurs
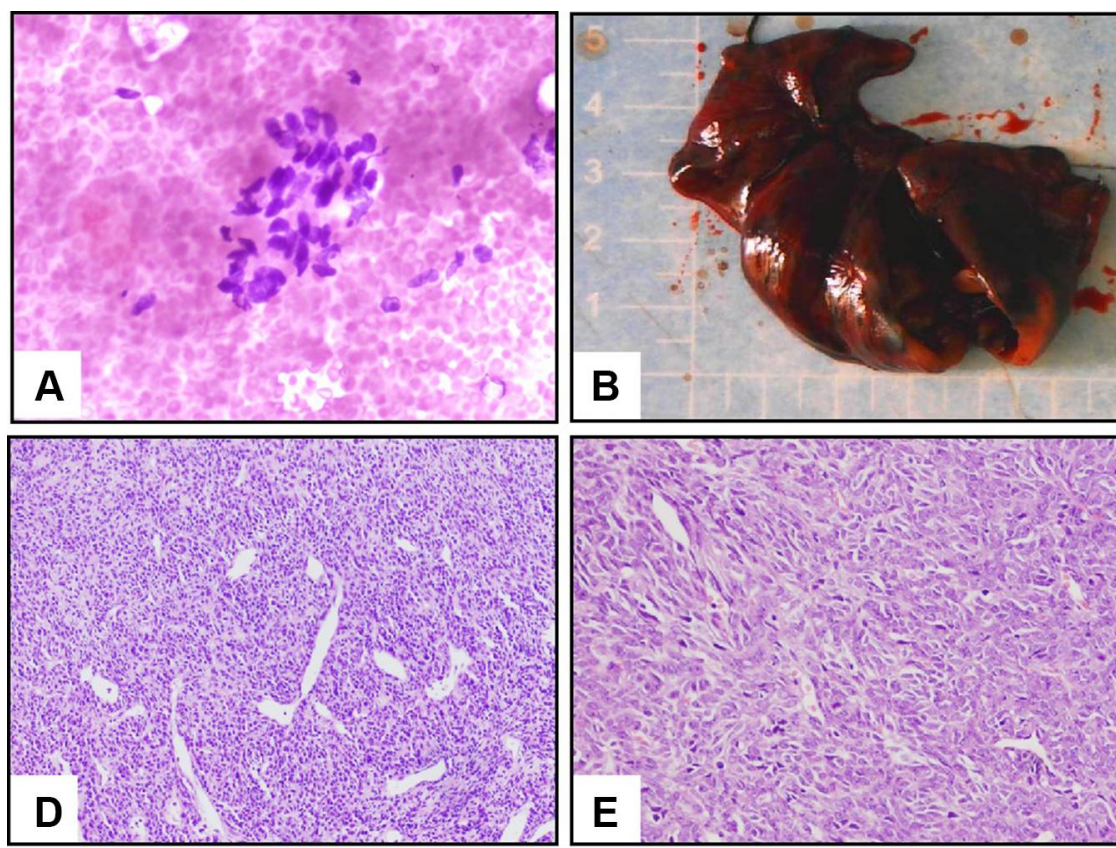

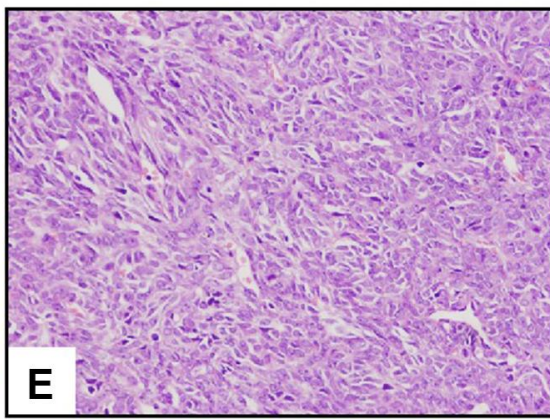

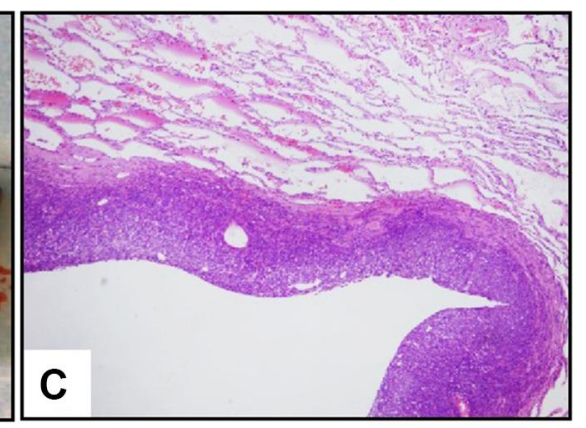

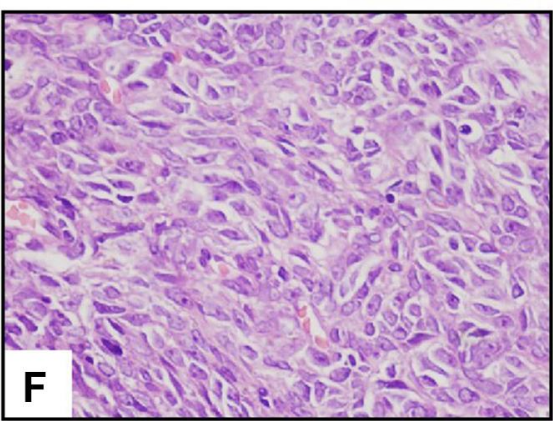

Figure I Gross and microscopic histopathological features of the pulmonary primitive neuroectodermal tumor. (A) Fine-needle cytology of the tumor (H\&E; magnification ×40); (B) Gross specimen of the tumor and surrounding lung tissue; (C) Location of the tumor in the lung tissue (H\&E; magnification $\times 40$ ); (D) Area with tumor cells arranged in a hemangiopericytoma-like pattern (H\&E; magnification $\times 100)$; (E) Homer-Wright chrysanthemum-shaped clusters can be observed in some areas (H\&E; magnification $\times 200$ ); (F) In some regions, cells were polygonal (H\&E; magnification $\times 400)$. 

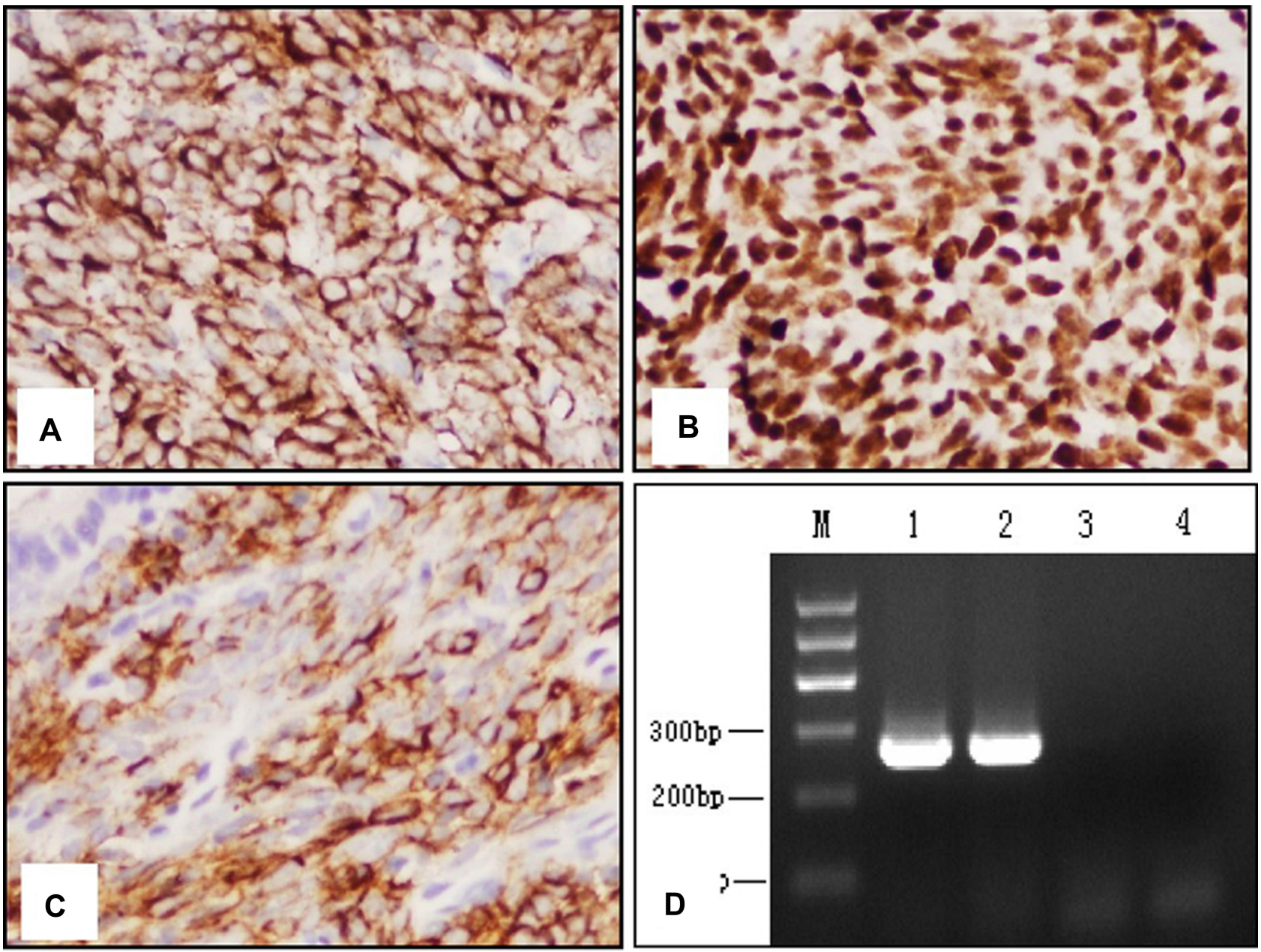

Figure 2 Immunohistochemical and molecular analyses of the pulmonary primitive neuroectodermal tumor. (A) Immunohistochemical staining for Vimentin showing diffuse membrane positivity (original magnification $\times 400$ ); (B) Immunohistochemistry image showing cells with diffuse FLI-I positivity (original magnification $\times 400)$; (C) Tumor cells showing diffuse membrane positivity for CD99 (original magnification $\times 400$ ); (D) Expression of the EWSRI-FLI-I fusion gene: (I) a case of Ewing sarcoma, (2) the present case, (3) a case of myxoid liposarcoma (negative control), and (4) blank control.

most commonly in children, adolescents, and young adults $(<35$ years old $){ }^{4}$ PNET is widely diagnosed through clinically and histologically identical tumors comprised of small round blue cells; these cells are uncommon entities, accounting for $5 \%$ of all small round cell tumor cases. ${ }^{5}$ Typically, PNET is a painful and aggressive tumor that may invade the chest wall, lungs, mediastinum, and heart. Despite the lungs being one of the common metastatic areas, cases of primary pulmonary PNETs are extremely rare. In our case, the patient presented with a one-week history of dry cough and low-grade fever without expectoration, fatigue, or other symptoms. CT imaging revealed a mass in the left upper lung lobe. Histopathological examination detected the proliferation of small round blue cells with neuroectodermic differentiation. Immunohistochemical analysis indicated positive expression of CD99, Fli-1, and vimentin. Finally, molecular pathology identified EWSR1-FLI1 fusion gene expression. Taken together, these findings supported the diagnosis of pulmonary PNET.

PNET can involve many parts of the body, Studies have reported that PNET occurs most commonly in the abdomen, kidneys, mediastinum and chest, nasal cavity, maxillary bone, adrenal glands, and retroperitoneal space, etc. Upon searching all available literature published in English journals and reports on primary pulmonary PNETs without thoracic wall involvement, we retrieved 21 studies describing a total of 28 cases (Table 1) ${ }^{6-26}$ Among 28 cases, the proportion of male patients was slightly higher than that of female patients (17:11). Of all patients, $87 \%$ were younger than 35 years old at disease onset (range, 8-67 years old), which is in accordance with the common characteristics of PNET. Tumor metastasis at diagnosis, large tumor size, and invasion of the heart are indicatives 
Table I Primary Pulmonary Primitive Neuroectodermal Tumor in Previous Reports

\begin{tabular}{|c|c|c|c|c|c|c|}
\hline Reference & Year & Age/Sex & Tumor Location & $\begin{array}{l}\text { Immunohistochemistry } \\
\text { (Positive) }\end{array}$ & Treatment & Follow-Up \\
\hline BAȘGÖZ 6 & 2017 & $58 / M$ & RLL & CD99, CD56, Vimentin, & $\mathrm{S}+\mathrm{CT}$ & $A \& W$ \\
\hline $\mathrm{Li} Q$ et $\mathrm{al}^{7}$ & 2017 & $12 / M$ & RLL & CD99, Vimentin, Syn & $\mathrm{CT}+\mathrm{RT}$ & $A \& W$ at 15 months \\
\hline Zhang $\mathrm{CH}^{8}$ & 2016 & $30 / \mathrm{F}$ & LLL & Vimentin, CD99, Syn, Fli-I, NSE & $\mathrm{S}+\mathrm{CT}$ & DOD at 20 months \\
\hline Narayan $\mathrm{R}^{9}$ & 2016 & $8 / F$ & RLL & CD99 & $\mathrm{S}+\mathrm{CT}$ & A\&W at 60 months \\
\hline Dong $M^{10}$ & 2015 & $16 / M$ & Multiple in both lung & CD99, Vimentin & $\mathrm{CT}$ & DOD at 5 months \\
\hline Gachechiladze ${ }^{\prime \prime}$ & 2014 & $3 I / F$ & Right lung & CD99, CD56, Vimentin & CT & DOD at I months \\
\hline Amita $^{12}$ & 2013 & $2 \mathrm{I} / \mathrm{F}$ & LUL & CD99, NSE, Vimentin, & $S+C R T$ & $A \& W$ at 3 months \\
\hline Andrei ${ }^{13}$ & 2013 & $31 / M$ & Lung & CD99, NSE, Vimentin & $S+C R T$ & DOD at 36 months \\
\hline $\operatorname{Lin}^{14}$ & 2013 & I9/M & Lung & CD99, NSE, Vimentin, & S & $A \& W$ at 4 years \\
\hline Weissferdt ${ }^{15}$ & 2012 & $\begin{array}{l}22 / M \\
27 / M \\
29 / F \\
56 / F \\
29 / M \\
31 / M\end{array}$ & $\begin{array}{l}\text { RUL } \\
\text { LUL } \\
\text { LUL } \\
\text { RLL } \\
\text { RUL } \\
\text { RML }\end{array}$ & $\begin{array}{l}\text { CD99, NSE, Vimentin } \\
\text { CD99, NSE, Vimentin } \\
\text { CD99, NSE, Vimentin } \\
\text { CD99, NSE, Vimentin } \\
\text { CD99, NSE, Vimentin } \\
\text { CD99, NSE, Vimentin }\end{array}$ & $\begin{array}{l}S \\
S+C T \\
S+C T \\
C T+S+C T \\
S \\
S+C T\end{array}$ & $\begin{array}{l}\text { NK } \\
\text { DOD at } 24 \text { months } \\
\text { DOD at } 36 \text { months } \\
\text { A\&W at } 11 \text { months } \\
\text { NK } \\
\text { DOD at } 54 \text { months }\end{array}$ \\
\hline $\mathrm{Mao}^{16}$ & 2012 & $28 / M$ & Multiple in both lung & CD99, Vimentin & CT & DOD at 12 months \\
\hline Ngow $^{17}$ & 2011 & $15 / M$ & Lung & CD99, NSE & CT & DOD at 12 months \\
\hline Antelo $^{18}$ & 2010 & $22 / F$ & Lung & CD99, Syn & $\mathrm{CT}$ & A\&W \\
\hline Gaude $^{19}$ & 2009 & $28 / M$ & L hilum & Syn, CgA & $S+C R T$ & DOD at 4 months \\
\hline Verfaillie $^{20}$ & 2009 & $33 / M$ & Lung & NSE, Vimentin, Syn & $\mathrm{S}+\mathrm{CRT}$ & DOD at 22 months \\
\hline $\operatorname{Lee}^{21}$ & 2007 & $67 / M$ & LLL & CD99, Vimentin, Syn & $\mathrm{S}+\mathrm{CT}$ & $A \& W$ \\
\hline Mikami ${ }^{22}$ & 2001 & $\mid 7 / F$ & RLL & CD99 & $\mathrm{S}+\mathrm{CRT}$ & DOD at 9 months \\
\hline $\mathrm{Kahn}^{23}$ & 2001 & $18 / M$ & RML & CD99, Vimentin, NSE & S & DOD at 24 months \\
\hline Baumgartner ${ }^{24}$ & 2001 & $26 / F$ & L hilum & CD99 & $\mathrm{CT}+\mathrm{S}+\mathrm{CRT}$ & DOD at 8 months \\
\hline Imamura ${ }^{25}$ & 2000 & $\begin{array}{l}30 / \mathrm{F} \\
41 / \mathrm{M}\end{array}$ & $\begin{array}{l}\text { RLL } \\
\text { LUL }\end{array}$ & $\begin{array}{l}\text { CD99, NSE } \\
\text { CD99, Vimentin, NSE }\end{array}$ & $\begin{array}{l}\mathrm{CT}+\mathrm{S}+\mathrm{CT} \\
\mathrm{CT}+\mathrm{S}\end{array}$ & $\begin{array}{l}A \& W \text { at } 16 \text { months } \\
A \& W \text { at } 22 \text { months }\end{array}$ \\
\hline Tsuji ${ }^{26}$ & 1998 & $\begin{array}{l}25 / \mathrm{F} \\
15 / \mathrm{M}\end{array}$ & $\begin{array}{l}\text { LLL } \\
\text { LLL }\end{array}$ & $\begin{array}{l}\text { CD99, NSE } \\
\text { CD99, NSE }\end{array}$ & $\begin{array}{l}S \\
S\end{array}$ & $\begin{array}{l}\text { DOD at } 24 \text { months } \\
\text { A\&W at } 24 \text { months }\end{array}$ \\
\hline
\end{tabular}

Abbreviations: M; male; F, female; RUL, right upper lobe; LUL, left upper lobe; RLL, right lower lobe; LLL, left lower lobe; RML, right middle lobe; NK, not known; CT, chemotherapy; S, surgery; RT, radiotherapy; CRT, chemoradiation; A\&W, alive and well; DOD, dead of disease.

of poor prognosis. Regarding treatment options, surgery is the preferred treatment, whereas chemo- and radiotherapy are the main treatment options for patients who are unable to undergo surgery due to tumor location or disease stage, but they are considered ineffective.

Most patients sought medical attention with symptoms of pneumonia, such as cough and low-grade fever, and had pulmonary nodules found on CT examination, which were then sent for biopsy. Pathological and immunohistochemical analyses were used to assist the diagnosis. Almost all cases showed CD99 positivity. Importantly, the disease needs to be distinguished from other small round cell lung tumors, including SCLC, metastatic neuroblastoma, alveolar rhabdomyosarcoma, synovial sarcoma, and non-Hodgkin's 
lymphoma. Among these, primary pulmonary PNET and SCLC - the most common small round cell tumor of to occur primarily in the lung-are the most similar. Immunohistochemical staining showed that neuroendocrine markers, such as Syn and $\mathrm{CgA}$ expression, were positive in both PNET and SCLC cases. Therefore, we recommend genetic testing to positively identify PNET cases through the detection of $(11 ; 22)$ ( $\mathrm{q} 24 ; \mathrm{q} 12)$ translocation, resulting in the fusion gene EWSR1-FLI1, which can be detected in most PNET patients.

The National Comprehensive Cancer Network guidelines recommend local treatment (surgery and/or radiotherapy) plus chemotherapy for treating tumors of the Ewing family. ${ }^{27}$ Although chemotherapy can improve the survival rate of patients and radiotherapy can provide local control, complications associated with these therapies have reduced their utilization. Rud et $\mathrm{al}^{28}$ and Qureshi et $\mathrm{al}^{29}$ have suggested that surgery, especially with a negative surgical margin, may have a more important role in PNET than in skeletal Ewing sarcoma. Therefore, surgery remains the gold standard treatment for PNET. In addition to conventional radio- and chemotherapy, molecular targeted therapy is an option for patients who cannot have surgery. A recent report suggested that pulmonary PNET with copy number loss (CNL) of the Von Hippel-Lindau (VHL) gene benefits from sunitinib treatment; after a fourmonth treatment with sunitinib, the patient achieved partial response according to the Response Evaluation Criteria in Solid Tumors guideline and the quality of life has improved significantly. ${ }^{8}$

For patients with pulmonary nodules who cannot undergo surgery due to disease stage or other contraindications, lung puncture can be used to detect the nature of the nodules. If the patient has pleural effusion or sputum, these specimens can be embedded in liquid paraffin and used for diagnosis. Under the microscope, these tissues should have few and morphologically atypical cells. Moreover, both PNET and SCLC cells are small round cells and have naked nuclei, and immunohistochemical staining may show positivity for neuroendocrine markers in both cancer types. Therefore, this rare primary pulmonary PNET can be easily misdiagnosed as SCLC. However, while SCLC is sensitive to chemoradiotherapy, PNET is not. Thus, in addition to cellular morphology and immunohistochemistry analyses, fusion gene detection analysis must be performed to accurately diagnose pulmonary PNET cases. For PNET originated in the lung, relevant clinical studies are mostly single-institution and small- scale because of the disease rarity. Moreover, the absence of guidelines for the diagnosis and treatment of primary pulmonary PNET imposes an additional challenge for clinicians in the oncology field.

\section{Conclusion}

Herein, we reported a rare case of primary pulmonary PNET. A review of the literature showed that early detection and surgical resection can greatly improve the survival of patients with PNET. Regarding pathological diagnosis, immunohistochemistry analysis should be combined with fusion gene detection to ensure an accurate diagnosis. The most reliable marker of PNET, including those of pulmonary origin, is the translocation or amplification of the EWSR1 gene. Moreover, early diagnosis is important for performing a radical surgical resection of the tumor and for administering a chemotherapeutic regimen with less intensity and side effects.

\section{Ethics and Consent}

Written informed consent was obtained from the patient for publication of this case report and the accompanying images. The images did not contain the patient records and information. This study was approved by the Clinical Research Ethics board of the First Affiliated Hospital, Shihezi University School of Medicine.

\section{Acknowledgments}

This work was supported by grants from the National Natural Science Foundation of China (no. 81860471 and no. 82002846), Youth Innovation Training Talent Program of Shihezi University (no. CXPY 201915), and Subject of Independent Project of Shihezi University (no. ZZZC201924A).

\section{Disclosure}

The authors have no conflicts of interest to disclose.

\section{References}

1. Kushner BH, Hajdu SI, Gulati SC, Erlandson RA, Exelby PR, Lieberman PH. Extracranial primitive neuroectodermal tumors. The Memorial Sloan-Kettering Cancer Center experience. Cancer. 1991;67 (7):1825-1829. doi:10.1002/1097-0142(19910401)67:7<1825::AIDCNCR2820670702>3.0.CO;2-3

2. Askin FB, Rosai J, Sibley RK, Dehner LP, McAlister WH. Malignant small cell tumor of the thoracopulmonary region in childhood: a distinctive clinicopathologic entity of uncertain histogenesis. Cancer. 1979;43(6):2438-2451. doi:10.1002/1097-0142(197906) 43:6<2438::aid-cncr2820430640>3.0.co;2-9 
3. Takanami I, Imamura T. The treatment of Askin tumor: results of two cases. J Thorac Cardiovasc Surg. 2002;123(2):391-392. doi:10.1067/ mtc.2002.120718

4. Dai J, He HC, Huang X, Sun FK, Zhu Y, Xu DF. Long-term survival of a patient with a large adrenal primitive neuroectodermal tumor: a case report. World J Clin Cases. 2019;7(3):340-346. doi:10.12998/ wjcc.v7.i3.340

5. Hameed M. Small round cell tumors of bone. Arch Pathol Lab Med. 2007;131(2):192-204. doi:10.1043/1543-2165

6. Başgöz BB, Aydin A, Ince S, Demirci I, Özcan A. Late onset of primary pulmonary primitive neuroectodermal tumor: a case report. Clujul Med. 2017;90(4):449-452. doi:10.15386/cjmed-765

7. Li Q, Liu Y, Yu Y. Antiangiogenic therapy for primitive neuroectodermal tumor with thalidomide: a case report and review of literature. Medicine (Baltimore). 2017;96(51):e9272. doi:10.1097/MD.0000000000009272

8. Zhang C, Zhang J, Wang G, et al. Benefit of Sunitinib in the treatment of pulmonary primitive neuroectodermal tumors: a case report and literature review. Oncotarget. 2016;7(52):87543-87551. doi:10.18632/oncotarget. 13896

9. Narayan R, Sreedevi J, Rana F, Mishra M, Mohanty R. Primary Pulmonary Primitive Neuro-Ectodermal Tumour (PNET) in an eight-year-old girl - a rare case. J Clin Diagn Res. 2016;10(11): ED01-ED02. doi:10.7860/JCDR/2016/19709.8839

10. Dong M, Liu J, Song Z, et al. Primary multiple pulmonary primitive neuroectodermal tumor: case report and literature review. Medicine (Baltimore). 2015;94(27):e1136. doi:10.1097/MD.0000000000001136

11. Gachechiladze M, Skarda J, Ibrahim M, et al. Primitive neuroectodermal tumor (PNET) of the lung in an adult woman. World J Surg Oncol. 2014;12:374. doi:10.1186/1477-7819-12-374

12. Amita RN, Sandhyamani S, Balasubramoniam KR. Primary primitive neuroectodermal tumor of lung: a case report. Indian J Pathol Microbiol. 2013;56(4):479-480. doi:10.1186/1477-7819-12-374

13. Andrei M, Cramer SF, Kramer ZB, Zeidan A, Faltas B. Adult primary pulmonary primitive neuroectodermal tumor: molecular features and translational opportunities. Cancer Biol Ther. 2013;14 (2):75-80. doi:10.4161/cbt.22635

14. Shi L, Guo Z, Wu X. Primary pulmonary primitive neuroectodermal tumor metastasis to the pancreas: a rare case with seven-year follow-up. Diagn Pathol. 2013;8:51. doi:10.1186/1746-1596-8-51

15. Weissferdt A, Moran CA. Primary pulmonary primitive neuroectodermal tumor (PNET): a clinicopathological and immunohistochemical study of six cases. Lung. 2012;190(6):677-683. doi:10.1007/ s00408-012-9405-9

16. Mao L, Wang H, Xie G, Zhang N, Liao G. Rare pulmonary primitive neuroectodermal tumor metastasizing to the right atrium: a case report. Med Oncol. 2012;29(4):2649-2653. doi:10.1007/s12032012-0200-5
17. Ngow HA, Wan Khairina WM. Cardiac metastasis: a rare involvement of primitive neuroectodermal tumour of the lung. Pathol Oncol Res. 2011;17(3):771-774. doi:10.1007/s12253-010-9328-9

18. Suárez Antelo J, Rodríguez García C, Montero Martínez C, Verea Hernando H. Sarcoma de Ewing pulmonar/tumor neuroectodérmico primitivo (PNET): aportación de un caso y revisión de la bibliografía [Pulmonary Ewing sarcoma/primitive neuroectodermal tumor: a case report and a review of the literature]. Arch Bronconeumol. 2010;46 (1):44-46. doi:10.1016/j.arbres

19. Gaude GS, Malur PR, Kangale R, Anurshetru S. Primitive neuro-ectodermal tumor of the lung in an adult. Lung India. 2009;26(3):89-91. doi:10.4103/0970-2113.53233

20. Verfaillie G, Hoorens A, Lamote J. Primary primitive neuro-ectodermal tumour of the lung. Acta Chir Belg. 2009;109 (3):381-384. doi:10.1080/00015458

21. Lee YY, Kim DH, Lee JH, et al. Primary pulmonary Ewing's sarcoma/primitive neuroectodermal tumor in a 67-year-old man. J Korean Med Sci. 2007;22 Suppl(Suppl):S159-63. doi:10.3346/jkms

22. Mikami Y, Nakajima M, Hashimoto $H$, et al. Primary pulmonary primitive neuroectodermal tumor (PNET). A case report. Pathol Res Pract. 2001;197(2):113-119; discussion 121-2. doi:10.1078/ 0344-0338-00019

23. Kahn AG, Avagnina A, Nazar J, Elsner B. Primitive neuroectodermal tumor of the lung. Arch Pathol Lab Med. 2001;125(3):397-399. doi:10.1043/0003-9985(2001)125<0397:PNTOTL >2.0.CO;2

24. Baumgartner FJ, Omari BO, French SW. Primitive neuroectodermal tumor of the pulmonary hilum in an adult. Ann Thorac Surg. 2001;72 (1):285-287. doi:10.1016/s0003-4975(00)02535-2

25. Imamura F, Funakoshi T, Nakamura S, Mano M, Kodama K, Horai T. Primary primitive neuroectodermal tumor of the lung: report of two cases. Lung Cancer. 2000;27(1):55-60. doi:10.1016/s0169-5002(99) 00078-1

26. Tsuji S, Hisaoka M, Morimitsu Y, et al. Peripheral primitive neuroectodermal tumour of the lung: report of two cases. Histopathology. 1998;33(4):369-374. doi:10.1046/j.1365-2559

27. Biermann JS. Updates in the treatment of bone cancer. $J$ Natl Compr Canc Netw. 2013;11(5 Suppl):681-683. doi:10.6004/jnccn.2013.0200

28. Rud NP, Reiman HM, Pritchard DJ, Frassica FJ, Smithson WA. Extraosseous Ewing's sarcoma. a study of 42 cases. Cancer. 1989;64(7):1548-1553.

29. Qureshi SS, Laskar S, Kembhavi S, et al. Extraskeletal Ewing sarcoma in children and adolescents: impact of narrow but negative surgical margin. Pediatr Surg Int. 2013;29(12):1303-1309. doi:10.1007/s00383-013-3409-2
OncoTargets and Therapy

\section{Publish your work in this journal}

OncoTargets and Therapy is an international, peer-reviewed, open access journal focusing on the pathological basis of all cancers, potential targets for therapy and treatment protocols employed to improve the management of cancer patients. The journal also focuses on the impact of management programs and new therapeutic agents and protocols on patient perspectives such as quality of life, adherence and satisfaction. The manuscript management system is completely online and includes a very quick and fair peer-review system, which is all easy to use. Visit http://www.dovepress.com/ testimonials.php to read real quotes from published authors. 